\title{
PENGARUH BUDAYA ORGANISASI, DISIPLIN KERJA DAN TUNJANGAN KINERJA TERHADAP KINERJA PEGAWAI PADA SEKRETARIAT KEPANITERAAN MAHKAMAH AGUNG RI
}

\author{
Ria Tresina \\ Universitas Budi Luhur, Jakarta. Indonesia \\ Email: rya_bee@yahoo.com
}

\begin{abstract}
Abstrak
Penelitian ini bertujuan untuk mengetahui adanya pengaruh antara Budaya Organisasi, Disiplin Kerja dan Tunjangan Kinerja terhadap Kinerja Pegawai. Penelitian ini menjadikan penelitian sebelumnya sebagai salah satu sumber literatur serta referensi. Namun penelitian ini memiliki perbedaan dengan penelitian sebelumnya yang pada umumnya terletak pada populasi atau sampel, variabel, tempat serta metode pengolahan data yang digunakan. Data penelitian diperoleh dari kuesioner yang disebarkan secara langsung kepada pegawai Kepaniteraan Mahkamah Agung. Pengolahan data dilakukan dengan menggunakan program SPSS versi 20.0 yang meliputi uji validitas, uji reliabilitas, uji korelasi, uji regresi linier berganda, dan uji asumsi klasik. Hasil penelitian menunjukkan bahwa secara parsial Disiplin Kerja berpengaruh signifikan terhadap Kinerja Pegawai sebesar t hitung (4.036) > t tabel (1.996). Tunjangan Kinerja berpengaruh signifikan terhadap Kinerja Pegawai sebesar t hitung (4.894) $>$ t hitung. Secara simultan menunjukkan adanya pengaruh signifikan antara Budaya Organisasi, Disiplin Kerja terhadap Kinerja sebesar $11.334>\mathrm{F}$ tabel sebesar 2.70 dan besarnya pengaruh adalah 32.4 $\%$.
\end{abstract}

Kata Kunci: budaya organisasi; disiplin kerja; tunjangan kinerja; kinerja

\section{Abstract}

More about background, purpose, up to, the results of research, and manai research This research aims to find out the influence between Organizational Culture, Work Discipline and Performance Allowance on Employee Performance. This research makes previous research as one of the sources of literature as well as reference. But this study has differences with previous studies that generally lie in populations or samples, variables, places and data processing methods used. The research data was obtained from questionnaires distributed directly to Supreme Court clerks. Data processing is done using the SPSS version 20.0 program which includes validity tests, reliability tests, correlation tests, multiple linear regression tests, and classical assumption tests. The results showed that partially Work Discipline had a significant effect on Employee Performance by $t$ calculated $(4,036)>t$ table (1,996). Performance Allowance has a significant effect on Employee Performance by $t$ calculated $(4,894)>t$ calculated. Simultaneously showing a significant influence between Organizational Culture, Work Discipline on Performance by 11,334 > F tables of 2.70 and the magnitude of influence is

$\begin{array}{llllll}\text { How to cite: } & \text { Tresina, R., (2021) Pengaruh Budaya Organisasi, Disiplin Kerja dan Tunjangan Kinerja terhadap Kinerja } \\ & \text { Pegawai pada Sekretariat Kepaniteraan Mahkamah Agung RI. Syntax Idea, 3(9), } \\ & \text { https://doi.org/10.36418/syntax-idea.v3i9.1492 } & & \\ \text { E-ISSN: } & \text { 2684-883X } & & & & \\ \text { Published by: } & \text { Ridwan Institute } & \end{array}$


pengaruh budaya organisasi, disiplin kerja, dan tunjangan kinerja terhadap kinerja pegawai pada sekretariat kepaniteraan Mahkamah Agung RI

$32.4 \%$. Abstract contains up to 250 words, single write spaces with italics (Italics) for English abstracts. Below the abstract are listed keywords consisting of six words, where the first word is again the forward. Abstract in Indonesian can be a translation of an English translation. Tif editor for abstract syning for reasons of abstract content.

Keywords: organizational culture; work discipline; performance allowance; performance

Received: 2021-08-22; Accepted: 2021-09-05; Published: 2021-09-20

\section{Pendahuluan}

Mahkamah Agung merupakan Lembaga Peradilan tertinggi di Indonesia yang memiliki tugas sebagai pengadilan tingkat akhir, selain itu tugas Mahkamah Agung adalah membina keseragaman dalam penerapan hukum melalui putusan Kasasi dan Peninjauan Kembali dengan tujuan menjaga agar semua hukum dan undang-undang diseluruh wilayah Negara Republik Indonesia diterapkan secara adil, tepat dan benar. dengan terjaganya penerapan hukum di Indonesia, diharapkan akan menimbulkan kepuasan bagi para pencari keadilan (Rokhim, 2014).

Sebagai lembaga peradilan tertinggi, Mahkamah Agung diwajibkan untuk mempertahankan performa kinerja pegawai agar dapat selalu memberikan pelayanan yang terbaik bagi para pencari keadilan. Tercapainya kepuasan para pencari keadilan bukanlah hal mudah, diperlukan adanya faktor-faktor yang dapat mempertahankan atau bahkan meningkatkan kinerja pegawai.

Menurut (Afandi \& Bahri, 2020) Kinerja adalah hasil kerja yang dapat dicapai oleh seseorang atau kelompok orang dalam suatu perusahaan sesuai dengan wewenang dan tanggung jawab masing-masing dalam upaya pencapaian tujuan organisasi secara legal, tidak melanggar hukum dan tidak bertentangan dengan moral dan etika.

Budaya organisasi sering juga disebut budaya kerja karena tidak bisa dipisahkan dengan kinerja Sumber Daya Manusia (SDM), makin kuat budaya organisasi, makin kuat pula dorongan untuk berprestasi. Budaya organisasi memang sulit didefinisikan secara tegas dan sulit diukur, namun bisa dirasakan oleh Sumber Daya Manusia (SDM) di dalam perusahaan tersebut. Oleh karena itu, suatu organisasi terbentuk dari kumpulan individu yang berbeda baik sifat, karakter, keahlian, pendidikan, dan latar belakang pengalaman dalam hidupnya, perlu ada pengakuan pandangan yang akan berguna untuk mencapai misi dan tujuan organisasi tersebut, agar tidak berjalan sendiri-sendiri (Indraswari \& Djastuti, 2011).

Implementasi dari sikap atau perpaduan antara nilai-nilai yang ditanamkan organisasi dalam rangka mencapai tujuan organisasi maka akan menimbulkan rasa kedisiplinan kerja bagi para pegawai (Soetrisno, 2016). Disiplin adalah perilaku seseorang yang sesuai dengan peraturan, prosedur kerja yang ada atau disiplin adalah sikap, tingkah laku, dan perbuatan yang sesuai dengan peraturan dari organisasi baik tertulis maupun tidak tertulis. Disiplin kerja yang ada pada pegawai Kepaniteraan dirasa 
telah baik akan tetapi masih ditemukannya oknum-oknum yang bersikap maupun bekerja tidak sesuai dengan tingkat kedisiplinan yang ada (Sari \& Hadijah, 2016).

Pada dasarnya manusia bekerja untuk memperoleh uang dalam memenuhi kebutuhan hidupnya. Dengan begitu, seorang pegawai akan lebih menghargai kerja keras dan menunjukkan loyalitas terhadap perusahaan apabila kebutuhan dasarnya telah terpenuhi. Menurut (Kadarisman, 2017) tunjangan merupakan tambahan penghasilan yang diberikan organisasi kepada pegawainya. Biasanya pembayaran tunjangan disatukan dalam daftar pembayaran gaji pegawai setiap bulannya.

Kinerja merupakan gambaran tingkat keberhasilan atau kegagalan pelaksanaan tugas pokok dan fungsi organisasi dalam mewujudkan sasaran, tujuan, visi dan misi organisasi. Dalam menentukan kinerja karyawan, instansi atau organisasi harusnya memiliki beberapa komponen yang menjadi alat ukur kinerja, antara lain: kualitas pekerjaan, kejujuran pegawai, inisiatif, kehadiran, sikap, kerjasama, keandalan, pengetahuan tentang pekerjaan, tanggung jawab dan pemanfaatan waktu kerja (Siregar, 2016).

Jadi apabila instansi atau organisasi merasa bahwa komponen-komponen kinerja di atas menurun, maka instansi atau organisasi harus segara mencari faktor penyebab terjadinya penurunan tersebut. Dengan kata lain, memperlihatkan kebutuhan dan keinginan karyawan seperti kemampuan apa yang harus mereka miliki dan pelajari serta pemberian motivasi yang bagaimana yang mereka inginkan. Setelah mengetahui kebutuhan dan keinginan dari pegawai tersebut, instansi atau organisasi harus berusaha untuk memenuhinya. Karena jika tidak, maka kinerja karyawan tidak akan mengalami peningkatan (Putong, 2015).

Untuk menghasilkan kinerja yang baik, ada beberapa faktor atau variabel yang mempengaruhi seperti pelatihan, budaya organisasi, motivasi, kepemimpinan, disiplin kerja dan tunjangan. Pertama, (Astutiningsih \& Prayekti, 2019) mengatakan bahwa Analisis Gaya Kepemimpinan Ki Hadjar Dewantara, Kompensasi dan Budaya Organisasi berpengaruh secara simultan dan positif signifikan terhadap kinerja karyawan dan Budaya Organisasi menjadi variabel yang paling dominan berpengaruh dalam penelitian ini. Kedua, (Feel, Herlambang, \& Rozzaid, 2018) mengatakan bahwa Disiplin Kerja, Budaya Organisasi dan Lingkungan Kerja mempengaruhi Kinerja Pegawai pada pada Kantor Kelurahan Sekarputih Kec. Tegalampel Kab. Bondowoso secara positif dan signifikan. Ketiga, (Nasution, 2019) mengatakan bahwa Remunerasi dan Semangat Kerja mempengaruhi Kinerja Pegawai pada Kantor Kejaksaan Negeri Medan.

Berangkat dari pemikiran bahwa sumber daya manusia merupakan faktor yang dominan dalam suatu organisasi maka penulis melakukan wawancara secara lisan kepada rekan kerja mengenai faktor-faktor yang berpengaruh terhadap kinerja pegawai maka penulis tertarik untuk mengadakan penelitian dengan judul Pengaruh Budaya Organisasi, Disiplin Kerja dan Tunjangan Kinerja terhadap Kinerja Pegawai Pada Sekretariat Kepaniteraan Mahkamah Agung RI (Larasati, 2018). 
Tujuan penelitian ini adalah menganalisis pengaruh budaya organisasi, pengaruh disiplin kerja, pengaruh tunjangan kerja serta pengaruh budaya organisasi terhadap kinerja pada sekretariat kepaniteraan Mahkamah Agung RI.

\section{Metode Penelitian}

Metode penelitian yang digunakan dalam penelitian ini adalah metode deskriptif dengan pendekatan kuantitatif (Rukajat, 2018). Metode penelitian deskriptif ini dilakukan untuk mengetahui keberadaan variabel mandiri, baik hanya pada satu variabel atau lebih (variabel yang berdiri sendiri atau variabel bebas) tanpa membuat perbandingan variabel itu sendiri dan mencari hubungan dengan variabel lain (Sugiyono, 2017a). Tujuan dari metode deskriptif ini adalah untuk membuat deskripsi, gambaran atau lukisan secara sistematis, faktual dan akurat mengenai fakta-fakta, sifatsifat serta hubungan antar fenomena yang diselidiki.

Jika dilihat dari tujuan penelitiannya, jenis penelitian ini dapat dikategorikan sebagai penelitian deskriptif analistis. Deskriptif analistis merupakan suatu metode penelitian yang menggambarkan atau menjelaskan data yang sifatnya aktual dan dilanjutkan dengan menganalisis untuk mencari hubungan, kaitan, dan pengaruh antara variabel yang satu dengan variabel yang lain. Dalam penelitian ini, pendekatan analisis deskriptif digunakan untuk mengetahui bagaimana kinerja pegawai dengan adanya budaya organisasi, disiplin kerja dan tunjangan kinerja di Sekretariat Kepaniteraan Mahkamah Agung RI.

Adapun populasi dalam penelitian ini adalah pegawai Sekretariat Kepaniteraan Kepaniteraan Mahkamah Agung Republik Indonesia yang terdiri dari 3 (tiga) Kabag dan 6 (enam) Subbag. Jumlah pegawai negeri sipil di Sekretariat Kepaniteraan Mahkamah Agung Republik Indonesia berjumlah 63 orang pegawai yang tidak memiliki jabatan.

Dalam penelitian ini teknik yang digunakan dalam pengambilan sampel adalah sampling jenuh. Sampling jenuh adalah teknik penentuan sampel bila semua anggota populasi digunakan sebagai sampel. Karena jumlah populasi relatif kecil (Sugiyono, 2017b). Jumlah populasi yang akan digunakan penelitian adalah sebanyak 63 orang responden, maka populasi tersebut seluruhnya peneliti jadikan responden dalam penelitian.

Teknik pengumpulan data pada penelitian ini menggunakan kuesioner (angket) yang ditujukan kepada seluruh Pegawai pada Sekretariat Kepaniteraan untuk diisi sesuai dengan pertanyaan atau pernyataan untuk memperoleh data yang dibutuhkan oleh peneliti. Kuesioner (angket) merupakan teknik pengumpulan data yang dilakukan dengan cara memberi seperangkat pertanyaan atau pernyataan tertulis kepada responden untuk dijawabnya. 


\section{Hasil dan Pembahasan}

\section{A. Hasil Penelitian}

1. Hasil Uji Deskriptif Variabel Budaya Organisasi (X1)

Tabel 1

Hasil Uji Deskriptif Variabel Budaya Organisasi (X1)

Descriptive Statistics

\begin{tabular}{|c|c|c|c|c|c|}
\hline & $\mathbf{N}$ & Min & Max & Mean & Sdt.Deviation \\
\hline $\mathrm{X} 1.1$ & 63 & 4 & 5 & 4.76 & .429 \\
\hline $\mathrm{X} 1.2$ & 63 & 3 & 5 & 4.24 & .588 \\
\hline $\mathrm{X} 1.3$ & 63 & 2 & 5 & 3.71 & .750 \\
\hline $\mathrm{X} 1.4$ & 63 & 3 & 5 & 3.78 & .728 \\
\hline $\mathrm{X} 1.5$ & 63 & 3 & 5 & 4.59 & .586 \\
\hline X1.6 & 63 & 2 & 5 & 3.89 & .882 \\
\hline $\begin{array}{c}\text { Valid N } \\
\text { (Wistlise) }\end{array}$ & 63 & & & & \\
\hline
\end{tabular}

Sumber: Data primer yang diolah, 2021

Berdasarkan Tabel 1 hasil uji deskriptif variabel budaya organisasi diatas dengan jumlah responden sebanyak 63 orang menunjukkan bahwa nilai minimum pada pernyataan X1.3, X1.6 adalah 2, pernyataan X1.2, X1.4, X1.5 adalah 3, X1.1 adalah 4, nilai maksimum pada pernyataan X1.1, X1.2, X1.3, X1.4, X1.5, X1.6, adalah 5, nilai mean (rata-rata) pada pernyataan X1.1 $=4,76$, pernyataan $\mathrm{X} 1.2=$ 4,24 , pernyataan $X 1.3=3,71$, pernyataan $X 1.4=3,78$, pernyataan $X 1.5=4,596$, pernyataan X1.6 $=3,89$, nilai standar deviasi atau simpangan baku pada pernyataan $\mathrm{X} 1.1=0,429$, pernyataan $\mathrm{X} 1.2=0,558$, pernyataan $\mathrm{X} 1.3=0,750$, pernyataan X1.4 =0,728, pernyataan X1.5 =0,586, pernyataan X1.6 $=0,882$.

2. Hasil Uji Deskriptif Variabel Disiplin Kerja (X2)

\section{Tabel 2}

Hasil Uji Deskriptif Variabel Disiplin Kerja (X2)

\begin{tabular}{cccccc}
\hline \multicolumn{6}{c}{ Descriptive Statistics } \\
\hline X1.1 & 63 & 3 & 5 & 4.52 & .618 \\
\hline X1.2 & 63 & 3 & 5 & 4.70 & .507 \\
\hline X1.3 & 63 & 2 & 5 & 3.87 & .707 \\
\hline X1.4 & 63 & 2 & 5 & 3.54 & .779 \\
\hline X1.5 & 63 & 3 & 5 & 3.76 & .750 \\
\hline X1.6 & 63 & 2 & 5 & 3.92 & .747 \\
\hline Valid N & $\mathbf{6 3}$ & & & & \\
(Wistlise) & & & & & \\
\hline
\end{tabular}

Sumber: Data primer yang diolah, 2021

Berdasarkan Tabel 2 hasil uji deskriptif variabel disiplin kerja (X2) diatas dengan jumlah responden sebanyak 63 orang menunjukkan bahwa nilai minimum pada pernyataan X2.3, X2.4, X2.6 adalah 2, pernyataan X2.1, X2.2, X2.5 adalah 3. Nilai maksimum pada pernyataan X2.1, X2.2, X2.3 , X2.4 , X2.5 , X2.6 adalah 5 , nilai mean (rata-rata) pada pernyataan $\mathrm{X} 2.1=4,52$, pernyataan $\mathrm{X} 2.2=$ 
4,70 , pernyataan X2.3 $=3,87$, pernyataan X2.4 $=3,54$, pernyataan X2.5 = 3,76, pernyataan X2.6 = 3,92. Nilai standar deviasi atau simpangan baku pada pernyataan X2.1 $=0,618$, pernyataan $\mathrm{X} 2.2=0,496$ dan pernyataan $\mathrm{X} 2.3=0,707$, pernyataan X2.4 $=0,779$, pernyataan X2.5 =0,734, pernyataan X2.6 = 0,747.

3. Hasil Uji Deskriptif Variabel Tunjangan Kinerja (X3)

Tabel 3

Hasil Uji Deskriptif Variabel Tunjangan Kinerja (X3)

Descriptive Statistics

\begin{tabular}{cccccc}
\hline & N & Min & Max & Mean & Sdt.Deviation \\
\hline $\mathrm{X} 1.1$ & 63 & 3 & 5 & 4.52 & .618 \\
\hline $\mathrm{X} 1.2$ & 63 & 3 & 5 & 4.70 & .496 \\
\hline $\mathrm{X} 1.3$ & 63 & 2 & 5 & 3.87 & .707 \\
\hline $\mathrm{X} 1.4$ & 63 & 2 & 5 & 3.54 & .779 \\
\hline $\mathrm{X} 1.5$ & 63 & 3 & 5 & 3.76 & .734 \\
\hline $\mathrm{X} 1.6$ & 63 & 2 & 5 & 3.92 & .747 \\
\hline $\begin{array}{c}\text { Valid N } \\
\text { (Wistlise) }\end{array}$ & $\mathbf{6 3}$ & & & & \\
\hline
\end{tabular}

Sumber: Data primer yang diolah, 2020

Berdasarkan Tabel 3 hasil uji deskriptif variabel tunjangan kinerja (X3) diatas dengan jumlah responden sebanyak 63 orang menunjukkan bahwa nilai minimum pada pernyataan X3.3, X3.4, X3.6 adalah 2, dan nilai X3.1, X3.2, X3.5 adalah 3. Nilai maksimum pada pernyataan X3.1, X3.2, X3.3, X3.4, X3.5, X3.6 adalah 5, nilai mean (rata-rata) pada pernyataan X3.1 $=4,52$, pernyataan $X 3.2=$ 4,70 , pernyataan X3.3 = 3,87, pernyataan X3.4 =3,54, pernyataan X3.5 = 3,76, pernyataan X3.6 = 3,92. Nilai standar deviasi atau simpangan baku pada pernyataan X3.1 =0,618, pernyataan X3.2 =0,496, pernyataan X3.3 = 0,707, pernyataan X3.4=0,779, pernyataan X3.5 =0,734, pernyataan X3.6 = 0,747.

4. Hasil Uji Deskriptif Variabel Kinerja Pegawai (Y)

Tabel 4

Hasil Uji Deskriptif Variabel Kinerja Karyawan (Y) Descriptive Statistics

\begin{tabular}{cccccl}
\hline & N & Min & Max & Mean & Std. Deviation \\
\hline Y1 & 63 & 2 & 5 & 4.05 & .792 \\
\hline Y2 & 63 & 3 & 5 & 4.52 & .618 \\
\hline Y3 & 63 & 3 & 5 & 4.70 & .496 \\
\hline Y4 & 63 & 2 & 5 & 3.87 & .707 \\
\hline Y5 & 63 & 2 & 5 & 3.54 & .779 \\
\hline Y6 & 63 & 3 & 5 & 3.76 & .734 \\
\hline Y7 & 63 & 2 & 5 & 3.92 & .747 \\
\hline Y8 & 63 & 2 & 4 & 3.24 & .615 \\
\hline Valid N(listwise) & $\mathbf{6 3}$ & & & &
\end{tabular}

Sumber: Data primer yang diolah, 2020 
Berdasarkan Tabel 4 hasil uji deskriptif variabel Kinerja Karyawan (Y) diatas dengan jumlah responden sebanyak 63 orang menunjukkan bahwa nilai minimum pada pernyataan Y1, Y4, Y5, Y7, Y8, adalah 2, pernyataan Y2, Y3, Y6 adalah 3 dan pernyataan Y6 adalah 4. Nilai maksimum pada pernyataan Y1, Y2, Y3, Y4, Y5, Y6, Y7 adalah 5.Nilai mean (rata-rata) pada pernyataan Y1 = 4,05, pernyataan $\mathrm{Y} 2=4,52$ pernyataan $\mathrm{Y} 3=4,70$, pernyataan $\mathrm{Y} 4=3,87$, pernyataan $\mathrm{Y} 5=3,54$, pernyataan $\mathrm{Y} 6=3,76$, pernyataan $\mathrm{Y} 7=3,92$, pernyataan $\mathrm{Y} 8=3,24$. Nilai standar deviasi atau simpanganbaku pada pernyataan $\mathrm{Y} 1=0,792$, pernyataan $\mathrm{Y} 2=0,618$, pernyataan $\mathrm{Y} 3=0,496$, pernyataan $\mathrm{Y} 4=0,707$, pernyataan $\mathrm{Y} 5=0,779$, pernyataan $\mathrm{Y} 6=0,734$, pernyataan $\mathrm{Y} 7=0,747$, pernyataan $\mathrm{Y} 8=0,615$.

\section{Kesimpulan}

Berdasarkan penelitian yang telah dilakukan serta analisa terhadap data yang didapat, maka dapat diambil kesimpulan sebagai berikut Budaya organisasi, disiplin kerja dan kinerja secara bersama-sama berpengaruh terhadap kinerja pegawai Sekretariat Kepaniteraan Mahkamah Agung RI.

Budaya Organisasi berpengaruh positif dan signifikan terhadap kinerja pegawai Sekretariat Kepaniteraan Mahkamah Agung RI, dari hasil pengolahan data variabel budaya organisasi memiliki nilai tertinggi dibandingkan dengan variabel disiplin kerja dan tunjangan kinerja. Maka dapat dikatakan budaya organisasi yang ada pada Mahkamah Agung RI merupakan budaya organisasi yang memiliki nilai baik, dianut secara bersama dan berpengaruh positif terhadap kinerja pegawai.

Disiplin kerja berpengaruh positif dan signifikan terhadap kinerja pegawai Sekretariat Kepaniteraan Mahkamah Agung RI. Tunjangan Kinerja berpengaruh positif dan signifikan terhadap kinerja pegawai Sekretariat Kepaniteraan Mahkamah Agung RI. 
pengaruh budaya organisasi, disiplin kerja, dan tunjangan kinerja terhadap kinerja pegawai pada sekretariat kepaniteraan Mahkamah Agung RI

\section{BIBLIOGRAFI}

Afandi, Ahmad, \& Bahri, Syaiful. (2020). Pengaruh Kepemimpinan Motivasi dan Disiplin Kerja Terhadap Kinerja Karyawan. Maneggio: Jurnal Ilmiah Magister Manajemen, 3(2), 235-246.Google Scholar

Astutiningsih, Lucya Friska, \& Prayekti, Prayekti. (2019). Analisis Gaya Kepemimpinan Ki Hadjar Dewantara, Kompensasi, Dan Budaya Organisasi Terhadap Kinerja. Upajiwa Dewantara: Jurnal Ekonomi, Bisnis Dan Manajemen Daulat Rakyat, 3(1), 30-42. Google Scholar

Feel, Nico Harumanu, Herlambang, Toni, \& Rozzaid, Yusron. (2018). Pengaruh Disiplin Kerja, Budaya Organisasi Dan Lingkungan Kerja Terhadap Kinerja Pegawai. Jurnal Penelitian IPTEKS, 3(2), 176-185. Google Scholar

Indraswari, Meyta, \& Djastuti, Indi. (2011). Pengaruh Budaya Organisasi Dan Motivasi Terhadap Kepuasan Kerja Dalam Mempengaruhi Kinerja Karyawan Kantor Unit PT Telkom Regional IV Semarang. Universitas Diponegoro. Google Scholar

Kadarisman, Muh. (2017). The Implementation Of Regional Autonomy In Depok City Post-Constitution 1945 Amandment. IMC 2016 Proceedings, 1(1). Google Scholar

Larasati, Sri. (2018). Manajemen Sumber Daya Manusia. Deepublish. Google Scholar

Nasution, Dito Aditia Darma. (2019). Pengaruh Remunerasi dan Semangat Kerja terhadap Kinerja Pegawai Pada Kantor Kejaksaan Negeri Medan. Jurnal Akuntansi Dan Bisnis: Jurnal Program Studi Akuntansi, 5(1), 71-80. Google Scholar

Putong, Iskandar. (2015). Kepemimpinan: Kajian Teoritis dan Praktis (Vol. 1). Buku\&Artikel Karya Iskandar Putong. Google Scholar

Rokhim, Abdul. (2014). Mediasi Menurut Peraturan Mahkamah Agung Republik Indonesia Nomor 1 Tahun 2008 Tentang Prosedur Mediasi Di Pengadilan. Masalah-Masalah Hukum, 43(3), 322-329. Google Scholar

Rukajat, Ajat. (2018). Pendekatan penelitian kuantitatif: quantitative research approach. Deepublish. Google Scholar

Sari, Ririn Nur Indah, \& Hadijah, Hady Siti. (2016). Peningkatan kinerja pegawai melalui kepuasan kerja dan disiplin kerja. Jurnal Pendidikan Manajemen Perkantoran (JPManper), 1(1), 204-214. Google Scholar

Siregar, Ahmad Bukhari. (2016). Evaluasi Kinerja Kepala Sekolah Menengah Kejuruan Se-Kabupaten Langkat Tahun 2015. Universitas Medan Area. Google Scholar

Soetrisno, Edy. (2016). Manajemen sumber daya manusia. Kencana. Google Scholar 
Ria Tresina

Sugiyono. (2017a). Metode Penelitian Kuantitatif. Google Scholar

Sugiyono. (2017b). MetodePenelitian Kuantitatif, Kualitatif dan R\&D. Bandung: PT Alfabet. Sugiyono. (2017). MetodePenelitian Kuantitatif, Kualitatif Dan R\&D. Bandung: PT Alfabet. Google Scholar

Copyright holder:

Ria Tresina (2021)

First publication right:

Syntax Idea

This article is licensed under:

(c) (i) (2) 